\title{
Banana-Shaped Liquid Crystals with Two Oligosiloxane End-Groups Field-Induced Switching of Supramolecular Chirality
}

\author{
Christina Keith, ${ }^{a}$ R. Amaranatha Reddy,${ }^{b}$ Ute Baumeister ${ }^{b}$ and Carsten Tschierske ${ }^{a *}$ \\ Martin-Luther University Halle-Wittenberg, ${ }^{a}$ Institute of Organic Chemistry, Kurt-Mothes Str. 2, D-06120 Halle; \\ ' Institute of Physical Chemistry, Mühlpforte 1, D-06108 Halle, Germany
}

\section{Origin of supramolecular chirality in the smectic phases of bent core molecules}
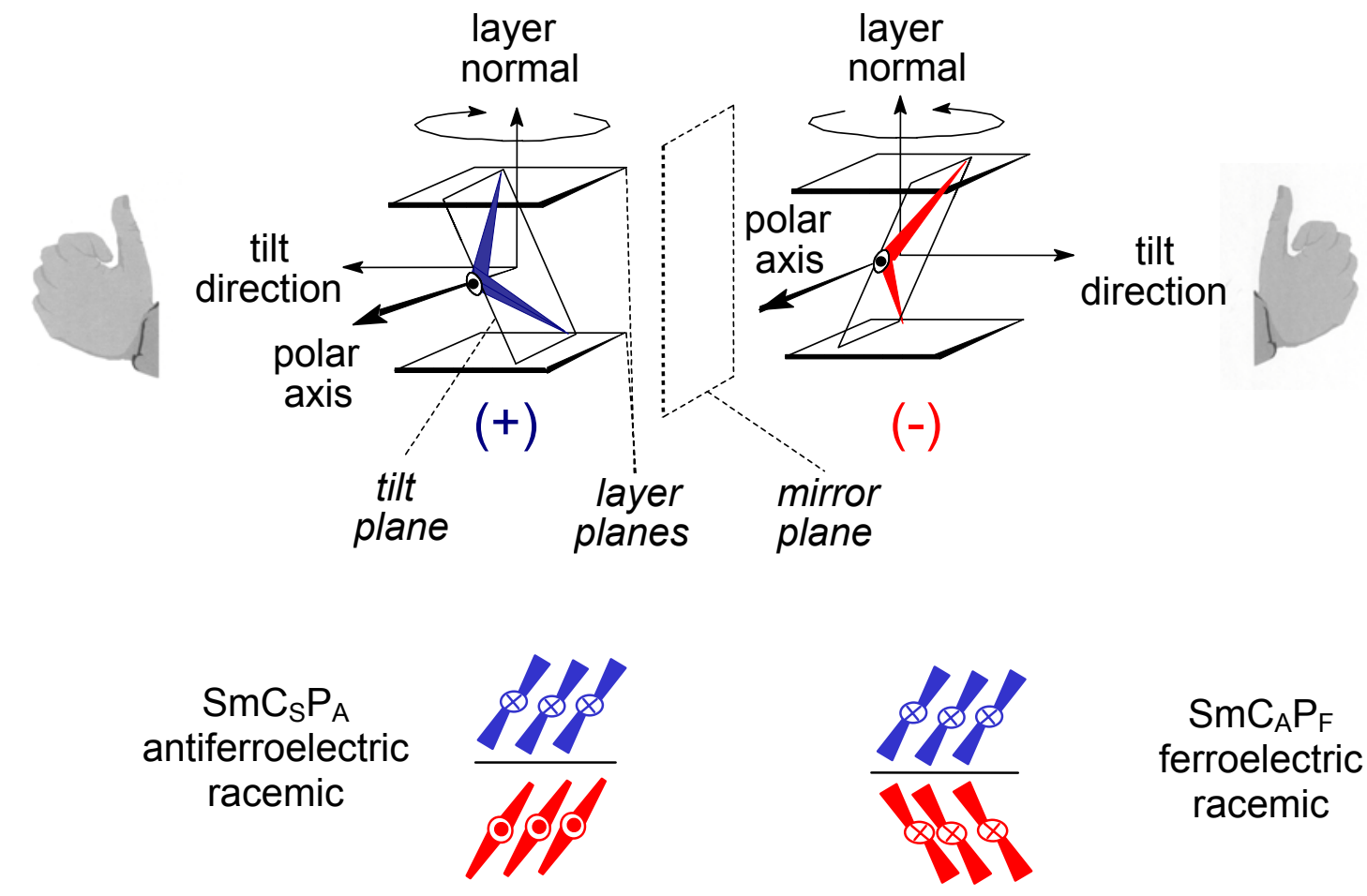

\author{
$\mathrm{SmC}_{\mathrm{A}} \mathrm{P}_{\mathrm{F}}$ \\ ferroelectric \\ racemic
}
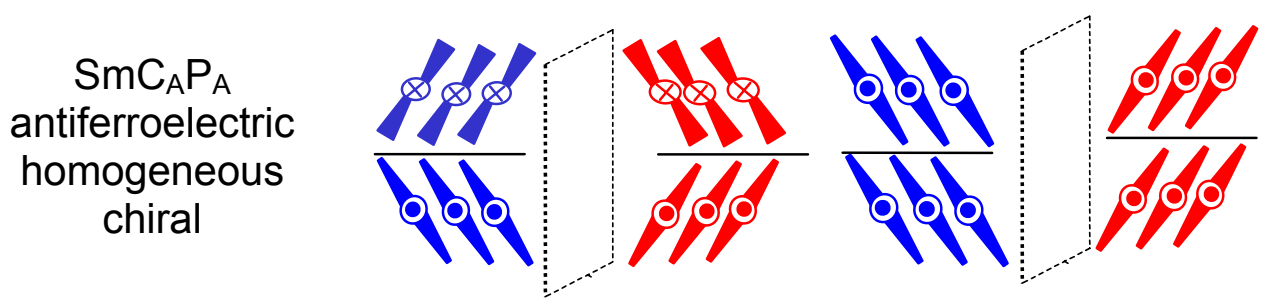

$\mathrm{SmC}_{S} \mathrm{P}_{\mathrm{F}}$ ferroelectric homogeneous

chiral

Figure S1. (a) Origin of the chirality within the smectic phases of bent-core molecules. Owing to the bend shape each molecule possesses a dipole moment in the molecular plane and perpendicular to the long axis of the molecules. Layer normal, tilt direction and the polar axis define either a right handed coordinate system $(+)$ shown in blue, whereas in the mirror image these vectors define a left handed system (-), shown in red. Changing either polarization direction or tilt direction changes the chirality sense of the layer (indicated by color). Changing both, polarization direction and tilt direction retains the chirality sense. Switching on a cone changes polarization direction and tilt direction and hence 
retains the chirality sense. Switching around the molecular long axis switches only the polarization direction without changing the tilt direction and therefore layer chirality is reversed (see Figure 2b,c in the main text). (b) The supramolecular arrangements resulting from the combination of the different tilt directions and polar directions (abbreviations: $\mathrm{C}_{\mathrm{S}}=$ synclinic tilt, $\mathrm{C}_{\mathrm{A}}=$ anticlinic tilt, $\mathrm{P}_{\mathrm{F}}=$ ferroelectric polar order, $\mathrm{P}_{\mathrm{A}}=$ antiferroelectric polar order). In two of them the layer chirality changes from layer to layer which corresponds to macroscopic racemic structures. In the two others the layer chirality is identical in adjacent layers. These macroscopically homogeneous chiral states can exist as mirror images. In macroscopic samples both enantiomeric organizations can be found in distinct regions (conglomerate), for more detailed explanations, see ref 2.

\section{Synthesis and analytical data of compound 1}

\section{3,4'-Bis(4-\{4-[11-(1,1,1,3,5,5,5-heptamethyltrisiloxane-3-yl)undec-1-yloxy]benzoyloxy $\}$ - benzoyloxy)biphenyl (1)}

Under an argon atmosphere 3,4'-bis\{4-[4-(10-undec-1-yloxy)benzoyloxy]benzoyloxy $\}$ biphenyl (synthesis will be reported in a separate paper) $(200 \mathrm{mg}, 0.21 \mathrm{mmol})$ was dissolved in anhydrous toluene (3 mL), 1,1,1,3,5,5,5-heptamethyltrisiloxane (93 mg, $0.42 \mathrm{mmol})$ and one drop of Karstedt's catalyst (platinum-divinyltetramethyl-siloxane complex in xylene, Gelest Inc.) were added to this mixture. After reaction was completed (detection by TLC, ca. $36 \mathrm{~h}$ ) the solvent was evaporated and the crude product was purified by centrifugal preparative thin layer chromatography (silica gel, $\left.\mathrm{CHCl}_{3}\right)$ followed by crystallisation from ethyl acetate to give $60 \mathrm{mg}(0.04 \mathrm{mmol}, 21 \%)$ of 1 . ${ }^{1} \mathrm{H}-\mathrm{NMR}$ $\left(400 \mathrm{MHz}, \mathrm{CDCl}_{3}\right): \delta 8.29\left(\mathrm{~d},{ }^{3} J=8.8 \mathrm{~Hz}, 2 \mathrm{H}, \mathrm{Ar}-\mathrm{H}\right), 8.28\left(\mathrm{~d},{ }^{3} J=8.9 \mathrm{~Hz}, 2 \mathrm{H}, \mathrm{Ar}-\mathrm{H}\right), 8.14\left(\mathrm{~d},{ }^{3} J=\right.$ $8.5 \mathrm{~Hz}, 4 \mathrm{H}, \mathrm{Ar}-\mathrm{H}), 7.65$ (d, $\left.{ }^{3} J=8.7 \mathrm{~Hz}, 2 \mathrm{H}, \mathrm{Ar}-\mathrm{H}\right), 7.50$ (d, $\left.{ }^{3} J=4.9 \mathrm{~Hz}, 2 \mathrm{H}, \mathrm{Ar}-\mathrm{H}\right), 7.44$ (m, 1H, ArH), $7.37\left(\mathrm{~d},{ }^{3} J=8.5 \mathrm{~Hz}, 2 \mathrm{H}, \mathrm{Ar}-\mathrm{H}\right), 7.36\left(\mathrm{~d},{ }^{3} J=8.7 \mathrm{~Hz}, 2 \mathrm{H}, \mathrm{Ar}-\mathrm{H}\right) 7.29\left(\mathrm{~d},{ }^{3} J=8.7 \mathrm{~Hz}, 2 \mathrm{H}, \mathrm{Ar}-\mathrm{H}\right)$, $7.21(\mathrm{~m}, 1 \mathrm{H}, \mathrm{Ar}-\mathrm{H}), 6.97\left(\mathrm{~d}, 4 \mathrm{H},{ }^{3} J=8.9 \mathrm{~Hz}, \mathrm{Ar}-\mathrm{H}\right), 4.04\left(\mathrm{t},{ }^{3} J=6.5 \mathrm{~Hz}, 4 \mathrm{H}, \mathrm{OCH}_{2}\right), 1.82(\mathrm{~m}, 4 \mathrm{H}$, $\left.\mathrm{OCH}_{2} \mathrm{CH}_{2}\right), 1.45\left(\mathrm{~m}, 4 \mathrm{H}, \mathrm{OCH}_{2} \mathrm{CH}_{2} \mathrm{CH}_{2}\right), 1.25\left(\mathrm{~m}, 28 \mathrm{H}, \mathrm{CH}_{2}\right), 0.44\left(\mathrm{t},{ }^{3} \mathrm{~J}=7.7 \mathrm{~Hz}, 4 \mathrm{H}, \mathrm{SiCH}_{2}\right), 0.05$ [s, 36H, Si $\left.\left(\mathrm{CH}_{3}\right)_{3}\right],-0.02\left(\mathrm{~s}, 6 \mathrm{H}, \mathrm{SiCH}_{3}\right) ;{ }^{13} \mathrm{C}-\mathrm{NMR}\left(125 \mathrm{MHz}, \mathrm{CDCl}_{3}\right): \delta 164.32(4 \mathrm{C}), 164.18(2 \mathrm{C})$, 163.73 (2C), 155.36 (2C), 151.27, 150.59, 142.00, 137.96, 132.34 (4C), 131.75 (4C), 129.78, 128.25 (2C), 126.78 (2C), 124.62, 122.05 (4C), 122.01 (4C), 120.95, 120.55, 120.39, 114.40, 68.44 (2C), 33.29 (2C), 29.69 (2C), 29.65 (4C), 29.44 (4C), 29.19 (2C), 26.08 (2C), 23.16 (2C), 17.74 (2C), 1.97 (12C), -0.14 (2C); ${ }^{29} \mathrm{Si}-\mathrm{NMR}\left(99.3 \mathrm{MHz}, \mathrm{CDCl}_{3}\right)$ : $\delta 6.81$ (4Si), -21.19 (2Si); Anal. Calcd. For $\mathrm{C}_{76} \mathrm{H}_{110} \mathrm{Si}_{6} \mathrm{O}_{14}: \mathrm{C}, 64.46 ; \mathrm{H}, 7.83$. Found: $\mathrm{C}, 64.70 ; \mathrm{H}, 7.65$.

Figure S2. Small angle XRD pattern of a well oriented sample of the $\mathrm{SmC}_{\mathrm{A}} \mathrm{P}_{\mathrm{A}}$ phase of 1 at $T=110^{\circ} \mathrm{C}$ showing the satellites along the equator. The absence or extremely week intensity of the 03 reflection can be attributed to the electron density profile parallel to the layer normal within one layer and might be due to the proportion and the location of the aromatic and/or the siloxane sublayers to the aliphatic sublayers.

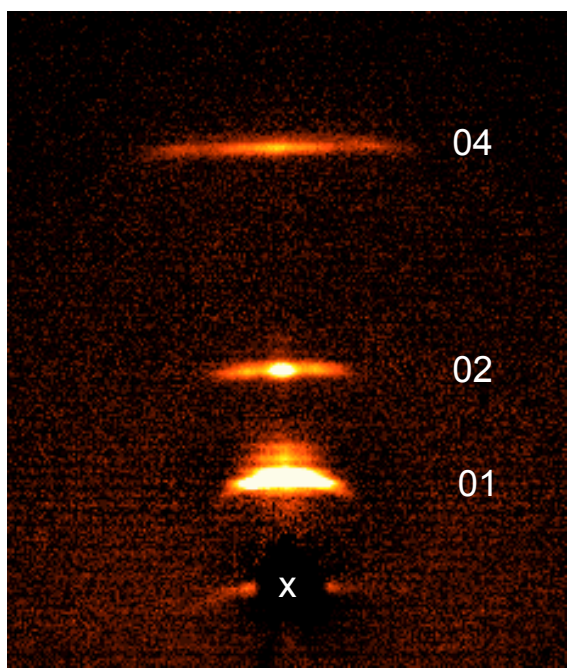

